\title{
Recommendation on screening for chlamydia and gonorrhea in primary care for individuals not known to be at high risk
}

\author{
Ainsley Moore MD MSc, Gregory Traversy MSc, Donna L. Reynolds MD MSc, John J. Riva DC PhD, \\ Guylène Thériault MD, Brenda J. Wilson MB ChB MSc MRCP (UK), Melissa Subnath MSc, Brett D. Thombs PhD; \\ for the Canadian Task Force on Preventive Health Care
}

- Cite as: CMAJ 2021 April 19;193:E549-59. doi: 10.1503/cmaj.201967

CMAJ Podcasts: author interview at www.cmaj.ca/lookup/doi/10.1503/cmaj.201967/tab-related-content

The guideline is available in French at www.cmaj.ca/lookup/doi/10.1503/cmaj.201967-f; see related article at www.cmaj.ca/lookup/ doi/10.1503/cmaj.210604

I

n Canada, Chlamydia trachomatis (chlamydia) and Neisseria gonorrhoeae (gonorrhea) are the most commonly reported sexually transmitted bacterial infections (STIS), ${ }^{1,2}$ with reported cases in the population increasing annually since $2000 .^{3}$ In 2018, reported cases were highest in people aged 15-29 years, with rates of $1.0 \%-1.9 \%$ for chlamydia and $0.2 \%-0.3 \%$ for gonorrhea in this population, ${ }^{4}$ while rates among individuals older than 30 years were less than $0.5 \%$ for chlamydia and less than $0.2 \%$ for gonorrhea. ${ }^{4}$ Many infected individuals, however, are asymptomatic or do not seek care, and are not included in reported cases. ${ }^{3}$ Taking into account underreporting, the true prevalence of chlamydia in people aged 15 to 29 years may be as high as 5\%-7\%. ${ }^{3-6}$

Consequences of untreated chlamydia in females can include cervicitis in $10 \%-20 \%,{ }^{7}$ pelvic inflammatory disease in $10 \%-$ $16 \%,{ }^{8,9}$ infertility in up to $5 \%,{ }^{10}$ chronic pelvic pain in $3 \%-8 \%,{ }^{10,11}$ and ectopic pregnancy in up to $2 \% .{ }^{10}$ Consequences of untreated gonorrhea may include rates of pelvic inflammatory disease that exceed those for chlamydia. ${ }^{12}$ In males, chlamydia may be associated with epididymitis in up to $7 \%$, with or without orchitis, ${ }^{6,13}$ and, very rarely, infertility. ${ }^{14}$ Consequences of chlamydia affecting both sexes include urethritis in $4 \%$ of females and up to $3 \%$ of males; ${ }^{15}$ pharyngitis; proctitis; reactive arthritis lasting longer than 6 months in 1\%-4\% (when considering both chlamydia and gonorrhea); ${ }^{16,17}$ and disseminated gonococcal infection in less than $1 \%$, which can rarely lead to sepsis, meningitis, endocarditis or osteomyelitis. ${ }^{18}$

Screening sexually active individuals for chlamydia and gonorrhea could reduce clinical complications and transmission, but should be done only if benefits from screening exceed harms $s^{19,20}$ and resource use is justifiable.

In Canada, STI screening is most commonly offered opportunistically by clinicians in a variety of primary care settings (e.g., family practice, sexual health clinics, school health centres) during visits that may or may not be for sexual health-related

\section{KEY POINTS}

- Chlamydia trachomatis and Neisseria gonorrhoeae are the most commonly reported sexually transmitted bacterial infections in Canada and can cause complications including pelvic inflammatory disease, chronic pelvic pain, ectopic pregnancy and infertility.

- Opportunistic offering of screening for chlamydia in primary care may reduce pelvic inflammatory disease in females, although the evidence is uncertain.

- Most patients likely prioritize the potential benefits of screening over harms; a small proportion of those eligible for screening may experience psychosocial harms of embarrassment, anxiety or stigma.

- The Canadian Task Force on Preventive Health Care recommends screening of sexually active individuals younger than 30 years for chlamydia and gonorrhea annually at primary care visits, as feasible (conditional recommendation; very lowcertainty evidence).

\section{Key messages for the public}

- Chlamydia and gonorrhea are common sexually transmitted infections that are treatable with antibiotics.

- If you are younger than age 30 and sexually active, your health care provider may offer screening for chlamydia and gonorrhea every year, even if you do not have symptoms.

- Screening is done to find and treat infections in people who aren't showing symptoms, which may reduce complications like pelvic inflammatory disease. These infections are often without symptoms.

- Talk to your doctor about screening more than once per year if you think you are at increased risk of infection (e.g., you have had a sexually transmitted infection, you have had unprotected sex, sex with multiple partners, or another reason).

- Chlamydia and gonorrhea infections are automatically reported to local public health units. This is to help with treatment for people who test positive and also with confidentially notifying sexual partners so that they may be tested and treated as required. 
concerns..$^{21}$ Opportunistic screening is distinct from a systematic population screening program, in which invitations for screening are sent to all eligible participants, monitored for uptake and evaluated through a centralized program, usually at the provincial level.

National guidance from the Public Health Agency of Canada currently recommends screening for chlamydia in pregnant women, annual screening for sexually active individuals younger than 25 years, and targeted screening of at-risk individuals older than 25 years (e.g., those with previous STIs, sex trade workers)..$^{21-23}$ This guidance is not based on formal systematic reviews and does not include recommendations for gonorrhea screening.

The last guideline on chlamydia screening from the Canadian Task Force on the Periodic Health Examination (now Task Force on Preventive Health Care) was published in 1996:24 it also did not include recommendations on gonorrhea. Therefore, the task force identified a need for an updated Canadian guideline that considers current evidence on the potential harms, benefits, and patient values and preferences of screening for chlamydia and gonorrhea.

\section{Scope}

This guideline is intended for clinicians in primary care settings who are positioned to offer opportunistic screening for chlamydia and gonorrhea directly to sexually active individuals who are not specifically seeking care for a possible STI and are not known to belong to a high-risk group. Readers should refer to relevant national, provincial or local guidance for the screening of individuals known to have specific high-risk behaviours (these will vary by jurisdiction, but may include having multiple sexual partners, previous STIs or sex without condoms ${ }^{22,25,26}$ ); testing of individuals seeking care for symptoms; pregnant individuals; and for selection of appropriate antibiotic treatment, partner notification, retesting and forensic testing strategies. The terms "male" and "female," when used, refer to sex (i.e., biological attributes, particularly the reproductive or sexual anatomy at birth), unless otherwise indicated.

\section{Recommendation}

We recommend opportunistic screening of sexually active individuals younger than 30 years who are not known to belong to a highrisk group, annually, for chlamydia and gonorrhea at primary care visits, using a self- or clinician-collected sample (conditional recommendation; very low-certainty evidence).

A summary of the recommendation is provided in Box 1 .

Providers should refer to relevant national, provincial or local guidance for screening of individuals known to belong to specific high-risk groups.

In the systematic review conducted for this guideline, all relevant studies (9 randomized controlled trials [RCTs], ${ }^{5,6,8,27-32}$ 1 controlled clinical trial ${ }^{33}$ and 2 retrospective cohort studies $^{34,35}$ ) on the potential benefits of chlamydia screening pro-
Box 1: Summary of recommendation for clinicians, policy-makers and patients

We recommend opportunistic screening of sexually active individuals younger than 30 years who are not known to belong to a high-risk group, annually, for chlamydia and gonorrhea at primary care visits, using a self- or clinician-collected sample (conditional recommendation; very low-certainty evidence).

Providers should refer to relevant national, provincial or local guidance for screening of individuals known to belong to specific high-risk groups.

vided indirect evidence (i.e., low applicability) on how and to whom screening would be offered in Canadian primary care. For example, 4 RCTs offered screening (regardless of uptake) by mailed invitation or through public education and screening encouragement ${ }^{6,29}$ rather than via direct discussion, and 1 cluster RCT provided clinic-level interventions (packages to help encourage clinicians to offer screening $)^{5}$ rather than direct clinician engagement, yielding low clinician participation and offers of screening. Three trials evaluated only those who accepted screening (acceptors of screening), 8,28,33 and 1 trial evaluated an offer to screen among those preselected owing to an interest in screening (offer to screen, preselected), ${ }^{31}$ which is indirect to the varied screening interest and acceptance among Canadian primary care patients. No studies on the effects of screening for gonorrhea for any outcomes of interest were identified in general-risk populations.

Eleven studies were identified on harms of screening for chlamydia. One RCT reported on adverse antibiotic events, ${ }^{5}$ and 10 uncontrolled cohort studies reported on psychosocial harms. ${ }^{20,36-44}$ No studies examined harms of screening for gonorrhea.

Fourteen studies examined values and preferences of screening for chlamydia or gonorrhea: 4 studies measured health state utility values (a measure of preference for being in a particular state of health ${ }^{45}$ ) for several of the benefit outcomes of screening for chlamydia and gonorrhea $11,46-48$ infection, and 10 (survey and qualitative) studies considered the relative importance of benefits to harms of chlamydia screening. ${ }^{49-58}$

\section{Benefits of screening}

\section{Offer to screen, regardless of uptake}

Meta-analysis of 2 RCTs ( $n=141362$ ) found very low-certainty evidence for little to no difference in pelvic inflammatory disease rate among females aged 16-29 years, over 1 to 3 years using an annual offer of chlamydia screening via self-collected vaginal samples (0.3 more in 1000 [95\% confidence interval $(\mathrm{Cl}) 7.6$ fewer to 11 more]). ${ }^{5,6}$

One RCT ( $n=15459)$ found very uncertain effects on infertility and very low-certainty evidence for little to no difference in ectopic pregnancy rates for females aged 21 to 24 years, over 9 years from a single offer of chlamydia screening via selfcollected vaginal samples (0.2 more in 1000 [95\% Cl 2.2 fewer to 3.9 more]). ${ }^{6}$ 
Meta-analysis of 3 RCTs ( $n=41709$ ) found low-certainty evidence for little to no difference in chlamydia transmission for individuals aged 15-29 years, over 1 to 3 years from a single offer of chlamydia screening via self-collected vaginal ${ }^{5,27}$ or urine samples ${ }^{24,26}$ (5.4 fewer per 1000 [95\% Cl 21.0 fewer to 12.6 more])..$^{27,29}$

Offer to screen, preselected individuals interested in screening One RCT ( $n=2607$ ) - among females aged $18-34$ years $(81 \%$ younger than $24 \mathrm{yr}$ ) preselected based on completing a prescreening questionnaire on chlamydia risk and then accepting an offer of a primary care appointment (suggesting an interest in being screened) - found low-certainty evidence that offering a single chlamydia screening via clinician-collected cervical swabs may reduce pelvic inflammatory disease (15.4 fewer per 1000 [95\% Cl 3.0 to 21.3 fewer], number needed to screen 65 [95\% Cl 47 to 333$]) .^{31}$

\section{Acceptors of screening}

Two RCTs and 1 controlled clinical trial $(n=30652)$ found lowcertainty evidence that females aged 15-29 years who complete a single chlamydia screen over $12-18$ months via self-collected vaginal $^{8,28}$ or urine samples ${ }^{33}$ may have a reduced risk for pelvic inflammatory disease over 1 year (5.7 fewer per $1000[95 \% \mathrm{Cl}$ 10.8 fewer to 1.1 more]). ${ }^{8,28,33}$

\section{Harms of screening}

One RCT ( $n=37543$ tested; $n=4574$ patients who received a diagnosis of chlamydia; number treated not reported) reported no adverse events from antibiotic treatment for chlamydia (very low-certainty evidence). ${ }^{5}$ Cohort studies ${ }^{20,36-44}$ reported on a variety of psychosocial harms of screening that were synthesized narratively; low- or very low-certainty evidence indicated that undergoing screening may lead to feelings of stigmatization (e.g., guilt, embarrassment, social disapproval) or anxiety about future infertility, sexuality or risk of infection in a small to moderate proportion of individuals (50-400 per 1000 individuals screened). The number of individuals affected in the entire eligible screening population is likely smaller. The exact duration and severity of these symptoms is unknown.

\section{Patient values and preferences}

Considering benefits relative to harms, surveys and qualitative studies found that individuals considering screening $(n=777)^{49-55}$ or undergoing screening $(n=77)^{56-58}$ placed greater relative importance on potential reproductive health and decreased transmission benefits than on anxiety or stigma of screening (very low-certainty evidence). No studies considered patient values related to adverse events from medication.

Similarly, the patient engagement study that the task force conducted for this guideline (described in Methods) showed that patients likely prioritize potential benefits of screening (all rated critical or important) over harms (all rated important) and have a strong preference to be screened; this was the case even when participants were presented with the evidence and its uncertainty. ${ }^{59,60}$
Considering the relative prioritization of different screening benefits, studies reporting health state utilities found that while utility values are similar across benefit outcomes, ${ }^{11,46-48}$ when considering durations of the health states, the avoidance of infertility and chronic pelvic pain may be more important to females than ectopic pregnancy, pelvic inflammatory disease or cervicitis (low-to-moderate certainty). ${ }^{61}$

\section{Resource use}

The task force did not conduct a systematic review on resource use or cost-effectiveness. In the judgment of the task force, the recommendation to screen all eligible patients at opportunistic visits could involve additional (moderate) costs, largely because of additional clinician time at these encounters and testing costs.

Cost-effectiveness estimates based on opportunistic screening scenarios suggest that high versus low rates of screening may improve cost-effectiveness, ${ }^{62}$ and that screening may be costeffective in Canada provided that the probability of chlamydia progressing to pelvic inflammatory disease is at least $10 \%,{ }^{63}$ although this is of very low certainty.

\section{Feasibility, acceptability, cost and equity}

Screening is currently a part of primary care practice and therefore judged to be feasible and likely acceptable to primary care practitioners and patients. Notably, 1 included RCT showed that patients accepted screening $80 \%$ of the time that it was offered ${ }^{64}$ (although the overall screening rate in this trial was low [24\%] because of lack of offer). ${ }^{5}$

The task force anticipates that public health and other policymakers will find the recommendation to screen acceptable, given the number of people affected, increasing incidence of chlamydia and gonorrhea infection, ${ }^{4}$ and availability of effective treatment.

In the judgment of the task force, the recommendation would likely improve health equity by normalizing screening as routine for sexually active individuals and thereby reducing important barriers to screening, such as fear of disapproval or discrimination and feelings of stigmatization. ${ }^{65}$ Additionally, because females carry most of the burden of the clinical consequences of infection, screening of males (a reservoir of infection for females) may improve health equity for females.

\section{Rationale}

\section{Benefits}

The indirectness (low applicability) of available evidence to inform opportunistic screening in Canada represents a major source of uncertainty, in addition to the very uncertain or lack of evidence for some outcomes of interest for chlamydia screening and for all outcomes of interest for gonorrhea screening. All evidence on benefits was of low or very low certainty, largely because of concerns about indirectness as well as imprecision (Appendix 1, available at www.cmaj.ca/lookup/doi/10.1503/ cmaj.201967/tab-related-content). Pelvic inflammatory disease may be reduced for those accepting and undergoing chlamydia 
Table 1: Effects of screening for chlamydia on pelvic inflammatory disease among general-risk individuals

\begin{tabular}{|c|c|c|c|c|c|c|c|}
\hline Outcome & Approach & $\begin{array}{l}\text { No. of studies } \\
\text { and design }\end{array}$ & $\begin{array}{l}\text { Follow- } \\
\text { up } \\
\text { period, } \\
\text { mo }\end{array}$ & $\begin{array}{c}\text { Rate in } \\
\text { unscreened } \\
\text { individuals }\end{array}$ & $\begin{array}{c}\text { Rate in } \\
\text { screened } \\
\text { individuals } \\
(95 \% \mathrm{Cl})\end{array}$ & $\begin{array}{c}\text { Absolute } \\
\text { difference } \\
(95 \% \mathrm{Cl})\end{array}$ & $\begin{array}{c}\text { Certainty of } \\
\text { evidence }\end{array}$ \\
\hline \multirow[t]{3}{*}{$\begin{array}{l}\text { Pelvic } \\
\text { inflammatory } \\
\text { disease }\end{array}$} & $\begin{array}{l}\text { Offer of screening, } \\
\text { all eligible }\end{array}$ & $\begin{array}{l}2 \text { RCTs }^{5,6} \\
n=141362\end{array}$ & $12-36$ & $\begin{array}{l}27.0 \text { per } \\
1000 \dagger\end{array}$ & $\begin{array}{l}27.3 \text { per } 1000 \\
(19.4 \text { to } 38.0)\end{array}$ & $\begin{array}{l}0.30 \text { more in } 1000 \\
\text { ( } 7.60 \text { fewer to } 11.0 \\
\text { more) }\end{array}$ & $\begin{array}{c}\oplus \ominus \ominus \ominus \\
\text { VERY LOW } \ddagger, \S\end{array}$ \\
\hline & $\begin{array}{l}\text { Offer of screening, } \\
\text { selected } \\
\text { individuals }\end{array}$ & $\begin{array}{l}1 \mathrm{RCT}^{31} \\
n=2607\end{array}$ & 12 & $\begin{array}{l}27.0 \text { per } \\
1000 \dagger\end{array}$ & $\begin{array}{l}11.6 \text { per } 1000 \\
(5.70 \text { to } 24.0)\end{array}$ & $\begin{array}{l}15.4 \text { fewer per } 1000 \\
\text { (3.00 to } 21.30 \text { fewer) }\end{array}$ & $\begin{array}{l}\oplus \oplus \ominus \ominus \\
\text { LOW §,ฯ }\end{array}$ \\
\hline & $\begin{array}{l}\text { Acceptors of } \\
\text { screening }\end{array}$ & $\begin{array}{l}2 \mathrm{RCTs}, 1 \mathrm{CCT}^{8,28,33} \\
n=30652\end{array}$ & $12-18$ & $\begin{array}{l}27.0 \text { per } \\
1000 \dagger\end{array}$ & $\begin{array}{l}21.3 \text { per } 1000 \\
(16.2 \text { to } 28.1)\end{array}$ & $\begin{array}{l}5.70 \text { fewer per } 1000 \\
\text { (10.8 fewer to } 1.10 \\
\text { more) }\end{array}$ & $\begin{array}{l}\oplus \oplus \ominus \ominus \\
\text { LOW } \neq, \S\end{array}$ \\
\hline \multicolumn{8}{|c|}{$\begin{array}{l}\text { Note: } \mathrm{CCT}=\text { controlled clinical trial, } \mathrm{Cl}=\text { confidence interval, } \mathrm{CT}=\text { Chlamydia trachomatis, PID = pelvic inflammatory disease, RCT = randomized controlled trial. } \\
\text { *These analyses represent results of studies that examined the effect of offering chlamydia or gonorrhea screening to all eligible individuals, regardless of level of uptake. One study } \\
\text { used an offer of screening approach in a preselected population of individuals interested in screening (offer of screening, selected individuals). } \\
\text { tThe effects without screening assumed that about } 6 \% \text { of the female population would have chlamydia (general-risk prevalence). For the outcome of PID, it was assumed that about } \\
13 \% \text { of females with chlamydia would develop PID }(0.78 \% \text { of the total population), and that about } 25 \%-30 \% \text { of all-cause PID is attributed to chlamydia (all-cause PID }=3.5 \text { times PID } \\
\text { from CT); } 0.78 \% \times 3.5=2.7 \% \text { prevalence of PID owing to chlamydia in the unscreened group. } \\
\text { †Serious concerns about indirectness. } \\
\text { §Serious concerns about imprecision. } \\
\text { "ISerious concerns about risk of bias. }\end{array}$} \\
\hline
\end{tabular}

screening $8,28,33$ and for those interested in being screened who are offered it (low certainty) ${ }^{31}$ (Table 1 ). Very uncertain evidence found little to no difference in pelvic inflammatory disease when chlamydia screening was offered, via mailed invitation or cliniclevel packages that encouraged screening. The task force judged that the true benefit of chlamydia screening when offered directly by Canadian primary care practitioners, who are positioned to identify those eligible and to offer screening opportunistically, would likely lie within this observed range of screening effectiveness (Table 1 ).

The recommendation to screen individuals younger than 30 years is based on the fact that almost all of the underlying evidence comes from studies of individuals in this age group. Further, the rates of chlamydia and gonorrhea are increasing among those aged 25-29 years in Canada, with rates and total cases similar to those aged $15-19$ years. ${ }^{4,60}$ Conversely, rates of chlamydia for those aged $30-39$ years are less than $50 \%$ of those for individuals $15-19$ and $24-29$ years, and less than $25 \%$ of those for individuals aged $20-24$ years. ${ }^{4}$ Similarly, rates in those aged 40-59 years are less than $25 \%$ of those in individuals aged 30-39 years. $^{4}$

Considering the properties of sexual networks, this recommendation to screen sexually active males as well is intended to reduce chlamydia and gonorrhea infection and its negative consequences in females, through their role in the transmission of these infections (although there were no available studies informing this rationale).

The task force made the recommendation to screen for gonorrhea as well (despite the lack of available evidence) given that many gonorrhea cases are asymptomatic; ${ }^{23,66}$ up to $40 \%$ of those with gonorrhea may have concurrent chlamydia; ${ }^{67-69}$ and current Canadian clinical and laboratory practice is to combine testing for gonorrhea with chlamydia using a single sample (most commercial nucleic acid amplification test [NAAT] assays test for both organisms simultaneously with a single specimen ${ }^{25}$ ). The incremental costs of screening for both chlamydia and gonorrhea (versus, for example, chlamydia alone) is uncertain but likely minimal, as some provincial schedules already include NAAT for chlamydia and gonorrhea together under a single price. ${ }^{70}$

\section{Harms}

The task force placed a lower priority on the very uncertain evidence of no serious adverse effects of antibiotic treatment for chlamydia and gonorrhea and uncertain evidence for psychosocial harms of screening (anxiety, shame and stigma) that are likely to be experienced by a small proportion of those eligible for screening.

The task force judged that the potential benefits of screening for chlamydia and gonorrhea to reduce pelvic inflammatory disease in females, albeit very uncertain, outweigh possible harms. Evidence suggests that most Canadian patients also prioritize the benefits over the harms of screening for chlamydia and gonorrhea, even when provided with the evidence and its uncertainty. ${ }^{59,60}$ Therefore, considering the balance of benefits and harms as well as evidence uncertainty, the task force provides a conditional recommendation in favour of opportunistic screening for chlamydia and gonorrhea in primary care for individuals younger than 30 years.

\section{Methods}

The Canadian Task Force on Preventive Health Care is an independent panel of clinicians and methodologists that makes recommendations on primary and secondary prevention in primary care (www.canadiantaskforce.ca). A working group of 
6 task force members developed this recommendation, with scientific support from the science team at the Public Health Agency of Canada.

The working group established the research questions and the analytical framework for the systematic review (Appendix 2, available at www.cmaj.ca/lookup/doi/10.1503/cmaj.201967/tab -related-content). The Evidence Review and Synthesis Centre at the University of Alberta (Edmonton) conducted the systematic review on which the recommendation is based, which evaluated the effectiveness of chlamydia and gonorrhea screening and the relative importance of screening outcomes (benefits and harms) to patients. ${ }^{61}$

A search for eligible studies was conducted using Ovid MEDLINE, Ovid Embase, Wiley Cochrane Library, CINAHL via EBSCOhost, and Ovid PsycINFO from database inception to Jan. 26, 2020, with supplemental searches for grey literature. For the relative importance of potential benefit outcomes, a 2013 review on health state utility values was also updated. ${ }^{71}$ The systematic review was registered (PROSPERO CRD42018100733), and a protocol for the review was published. ${ }^{13}$

In the systematic review, potential benefits of screening examined included reduced pelvic inflammatory disease, ectopic pregnancies, cervicitis and chronic pelvic pain in females; and for both females and males, reduced infertility and transmission (prevalence). Potential harms examined included serious adverse antibiotic reactions and negative psychosocial implications of screening (e.g., anxiety, sexual relationship distress including partner violence, stigmatization, blame). Thresholds for minimally important differences in benefit outcomes were determined before the task force examined the results. Details can be found in the systematic review..$^{13,61}$

The task force used the Grading of Recommendations, Assessment, Development and Evaluation (GRADE) approach to determine the certainty of evidence and strength of recommendation (Box 2). See Appendix 3, available at www.cmaj.ca/lookup/ doi/10.1503/cmaj.201967/tab-related-content. The entire task force approved the recommendations.

More information about the task force's methods are available at the task force website (http://canadiantaskforce.ca/ methods).

\section{Patient engagement}

The Knowledge Translation team at St. Michael's Hospital (Toronto) engaged members of the public from across Canada, recruited via advertisements on public websites (i.e., Craigslist and $\mathrm{Kijiji),} \mathrm{on} \mathrm{behalf} \mathrm{of} \mathrm{the} \mathrm{task} \mathrm{force} \mathrm{at} 2$ stages of guideline development. As a first step, 16 sexually active participants ( 9 identified as female, and 7 identified as male) aged 24-38 years rated the importance of screening outcomes via online survey and participated in a focus group to share their rationale for their ratings and discuss factors that affect the perceived importance of various outcomes. ${ }^{59,75}$ Outcomes considered critical and important to decision-making by both participants and task force members were included in the systematic review. After the evidence review was completed, 17 different sexually active participants aged $24-38$ years (13 participants

\section{Box 2: Grading of recommendations}

Recommendations are graded according to the Grading of Recommendations Assessment, Development and Evaluation system (GRADE). ${ }^{72}$ Whether a recommendation is strong or conditional is based on considerations such as certainty in the effects of an intervention, including magnitude, as well as estimates of how patients value and prioritize outcomes, variability of these estimates and wise use of resources.

\section{Strong recommendations}

- Strong recommendations are those for which the Canadian Task Force on Preventive Health Care is confident that the desirable effects of an intervention outweigh its undesirable effects (strong recommendation for an intervention) or that the undesirable effects of an intervention outweigh its desirable effects (strong recommendation against an intervention). A strong recommendation implies that most people will be best served by the recommended course of action.

- Strong recommendations are typically based on high-certainty evidence (i.e., high confidence in the estimate of the effect of an intervention). Strong recommendations may recommend in favour of an intervention (when there is high confidence of net benefit) or against an intervention (when there is high confidence of net harm). However, there are circumstances in which a strong recommendation may be considered based on low- or very lowcertainty evidence, or when there is absence of evidence. ${ }^{73}$

- When there is an absence of evidence to provide confidence that there is benefit from implementing a new prevention service or when a conclusion of possible benefit requires a high level of speculation on linkages of uncertain evidence, but there is high certainty that some patients would be harmed or scarce health care resources expended, the task force may make a strong recommendation against service implementation. ${ }^{74}$ This is consistent with the GRADE approach, in which strong recommendations are sometimes made with low-certainty evidence combined with high certainty of harm or resource implications, and with the value that the task force places on using scarce primary care resources wisely. ${ }^{74}$

\section{Conditional recommendations}

- Conditional recommendations are those for which the desirable effects probably outweigh the undesirable effects (conditional recommendation in favour of an intervention) or undesirable effects probably outweigh the desirable effects (conditional recommendation against an intervention) but appreciable uncertainty exists. Conditional recommendations are made when the certainty of evidence is lower, when the margin between desirable and undesirable consequences is small and the balance depends on patient values and preferences, or when there is high variability in the values and preferences of patients. Conditional recommendations may also be applied when the balance of cost and benefits is ambiguous, key stakeholders differ about the acceptability or feasibility of the implementation, or the effects on health equity are unclear.

- In certain cases where a conditional recommendation for an intervention is made, clinicians are encouraged to engage in shared decision-making, to recognize that different choices will be appropriate for individual patients, and to help each person arrive at a management decision consistent with their values and preferences.

Evidence is graded as high-, moderate-, low- or very low-certainty, based on how confident the task force is that the estimates of effect are correct. 
identified as male, 3 identified as female, and 1 identified as nonbinary) rated the importance of screening outcomes via online survey, this time after being provided with a summary of systematic review results. ${ }^{60}$

Knowledge translation tools to support recommendation implementation, informed by feedback from clinicians and patients, were developed (available at https://canadiantaskforce. ca/tools-resources/chlamydia-and-gonorrhea/).

\section{External and content expert review}

The protocol, ${ }^{13}$ systematic review ${ }^{61}$ and draft guideline were each reviewed by stakeholders, peer reviewers, and clinical and content experts (see Acknowledgements). Clinical and content experts served as advisors to the working group; they participated in working group meetings and reviewed documents for accuracy, but did not have input into or vote on the direction or strength of recommendations.

\section{Management of competing interests}

The task force follows Guidelines International Network principles for disclosures of interests and management of competing interests. ${ }^{76,77}$ The task force's oversight committee for evaluating and adjudicating competing interests consists of the task force chair and vice-chair and the director of the Global Health and Guidelines Division of the Public Health Agency of Canada. ${ }^{77}$

Funding for the task force is provided by the Public Health Agency of Canada. The task force did not consider the views of the funding body in developing the guideline.

All task force members are required to disclose financial and other relevant interests annually when new topics are selected and at each in-person meeting of the task force (3 times per year). These disclosures are available on the task force website (https://canadiantaskforce.ca/about/members/). There were no conflicts of interest among task force members for this guideline.

Clinical and content experts also disclose relevant interests at the outset of their participation and annually thereafter (see Appendix 4, available at www.cmaj.ca/lookup/doi/10.1503/ cmaj.201967/tab-related-content). The task force did not judge any disclosures to represent conflicts of interest that precluded participation as a clinical or content expert.

\section{Implementation}

To implement this screening recommendation, clinicians in primary care settings are advised to identify individuals who are eligible for screening (sexually active individuals younger than 30 years) and not seeking testing for a possible STI, and to offer chlamydia and gonorrhea screening opportunistically (i.e., without requiring a separate screening visit, and not only during sexual health visits). As noted above, results from $1 \mathrm{RCT}$ suggest that patient acceptance of screening is high when offered. ${ }^{64}$ As individuals at high risk of chlamydia and gonorrhea infection may not always readily self-identify or be easily identified by clinicians, this routine offer of screening applies to all sexually active individuals without clinician knowledge of their membership of a high-risk group. Sexually transmitted infections are associated with shame, embarrassment and substantial stigma, which could prevent patients from seeking screening and treatment. ${ }^{65,78}$ Routinely offering screening to all sexually active individuals has been suggested as one way to reduce stigma associated with STI testing. ${ }^{78}$ Those seeking testing or who are known to belong to a high-risk group should be managed according to relevant national, provincial or local guidance applicable to those populations. Sexual activity can be generally defined as ever having oral, vaginal or anal intercourse.

Informed consent, which is required for STI testing, is an additional implementation consideration. The main issues to address are those related to privacy, reporting of positive test results to local public health offices, and potential partner notification. Screening for sexually transmitted infection may cause embarrassment and anxiety for some patients. Offering screening requires sensitivity to stigmatization and fear of social disapproval, especially regarding gender, culture, behaviour and other vulnerabilities.

Although the optimal screening interval is unknown, an annual offer of screening may be appropriate for individuals at general risk, recognizing that encounters with primary care may occur less frequently. Most identified studies used annual screening ${ }^{61}$ and, in 1 study, most pelvic inflammatory disease cases occurring within 1 year were in individuals who were chlamydia negative at baseline (general risk). ${ }^{8}$ A false-positive result could cause harm without benefit to some individuals. This is particularly relevant when prevalence of chlamydia in the population is lower (e.g., 2\%-3\%), where the number of false positives from NAAT tests may be quite high (e.g., about $30 \%-60 \%$ at specificities of $97 \%-99 \%$ ).

Although we did not identify evidence that would allow recommendation of specific screening strategies, acceptability and uptake of screening ${ }^{79-81}$ may be improved by minimally invasive sample collection methods, of which self-collected vaginal swabs from females and urine samples from males are the most accurate (NAAT). ${ }^{82}$ Clinician-collected swabs are likely acceptable and feasible during certain encounters (e.g., Pap testing)..$^{83}$ Ultimately, patient preference and the clinical scenario will likely dictate the preferred sampling method. Clinicians are reminded to consider pharyngeal and rectal swabs if clinically warranted, although we did not identify any evidence to evaluate screening using samples from these sites.

In cases of actual or suspected child abuse, clinicians are directed to their local, provincial and territorial authorities (public health offices, child protection services, pediatricians and clinical experts), for STI testing, treatment, reporting and management.

\section{Monitoring and evaluation}

Rates of offer and uptake of screening among patients in primary care settings are a key performance measure for this guideline. Rates of reported chlamydia and gonorrhea infections represent another performance metric. 
Table 2 (part 1 of 2): Canadian (national and provincial) and international guidelines on screening for chlamydia and gonorrhea

\section{Organization}

Canadian Task Force on Preventive Health Care (current guideline, 2021)

Public Health Agency of Canada $(2020)^{22}$

Public Health Ontario $(2018)^{25}$

Ministère de la santé et des services sociaux du Québec $(2019)^{26}$

US Preventive Services Task Force $(2014)^{84}$

Public Health England (2018) ${ }^{85}$

\section{Recommendation}

We recommend opportunistic screening of sexually active individuals younger than $30 \mathrm{yr}$, who are not known to belong to a high-risk group, annually, for chlamydia and gonorrhea, at primary care visits, using a self- or clinician-collected sample (conditional recommendation; very low-certainty evidence).

\section{Chlamydia}

Screening for Chlamydia trachomatis is recommended for anyone with risk factors for infection. Screening recommendations for the detection of $C$. trachomatis:

Annual screening:

- Age $<25 \mathrm{yr}$

- Gay, bisexual, and other men who have sex with men and transgender populations

Targeted screening:

- Offer screening and repeat screening based on risk factors in those aged $\geq 25 \mathrm{yr}$

\section{Gonorrhea}

Offer screening to asymptomatic sexually active individuals with risk factors for gonorrhea. In Ontario, risk factors for gonorrhea of particular importance among those with unprotected sexual exposure include:

- Sexually active women younger than $25 \mathrm{yr}$

- Sexually active men who have sex with men

- Other risk factors as listed in the Canadian Guidelines on Sexually Transmitted Infections ${ }^{23}$

When performing concurrent testing for gonorrhea and chlamydia, use:

- Urine NAAT for males

- Vaginal NAAT (first-line) or urine NAAT (second-line) for females when a pelvic examination is not being conducted

- Cervical NAAT or vaginal NAAT (first-line) or urine NAAT (second-line) for females when a pelvic examination is being conducted

\section{Chlamydia}

Screening at least annually is recommended for:

- Men and women aged $25 \mathrm{yr}$ and younger who are sexually active with no other risk factors

- Men and women with new sexual partners or with more than 1 concurrent partner since their last test

- Individuals who have had an anonymous partner or more than 3 sexual partners in the last year

- Men who have sex with men

- Sex workers or their clients

- (In some cases) Individuals originating from a region where sexually transmitted and blood-borne infections are endemic

\section{Gonorrhea}

Screening at least annually is recommended for:

- Men (depending on region) and all women aged $25 \mathrm{yr}$ and younger who are sexually active and have no other risk factors

- Women with new sexual partners or with more than 1 concurrent partner since their last test

- Individuals who have had an anonymous partner or more than 3 sexual partners in the last year

- Men who have sex with men

- Sex workers or their clients

- (In some cases) Individuals originating from a region where sexually transmitted and blood-borne infections are endemic

\section{Sexually active women}

The USPSTF recommends screening for chlamydia in sexually active women aged 24 years and younger and in older women who are at increased risk for infection (Grade B recommendation).

The USPSTF recommends screening for gonorrhea in sexually active women aged 24 years and younger and in older women who are at increased risk for infection (Grade B recommendation).

\section{Sexually active men}

The USPSTF concludes that the current evidence is insufficient to assess the balance of benefits and harms of screening for chlamydia and gonorrhea in men (I statement).

\section{Chlamydia}

Annually or on change of sexual partner, tests should be offered to men and women younger than 25 years who have ever been sexually active.

Providers should use every opportunity to offer chlamydia screening across primary care and access to services for sexual and reproductive health and genitourinary medicine. 


\section{Organization}

Australasian Sexual Health Alliance $(2018)^{86}$

\section{Recommendation}

Test for chlamydia in the following situations:

- Aged $<30 y r$ and sexually active

- Partner change in the last 12 months

- Have had an STI in past 12 months

- Have had a sexual partner with an STI

- At increased risk of complications of an STI; e.g., termination of pregnancy or intrauterine device insertion

- Signs or symptoms suggestive of chlamydia

- Patient requests a sexual health check

Note: NAAT = nucleic acid amplification test, STI = sexually transmitted infection, USPSTF = United States Preventive Services Task Force.

\section{Other guidelines}

Guidelines from several groups within Canada $22,25,26$ and internationally ${ }^{84-86}$ similarly recommend that clinicians opportunistically offer screening to sexually active individuals for chlamydia. Some, but not all, also include recommendations to screen for gonorrhea (Table 2). The present recommendation extends to age 29 years (see recommendation rationale above), ${ }^{4}$ whereas other guidelines recommend screening to age 25 years, except for Australia, which recommends screening to age 30 years.

\section{Gaps in knowledge}

We did not identify any trials that carried out screening for chlamydia or gonorrhea in a manner consistent with how screening is offered directly to patients, opportunistically, in Canadian primary care. There was also limited evidence on health outcomes of screening for chlamydia or gonorrhea in males or their specific female partners (considering sexual networks). Almost no studies included participants older than 30 years (which may be because of the low prevalence in this population). Studies comparing the impacts of different screening intervals or different screening strategies in primary care settings on health outcomes are required.

\section{Limitations}

Thresholds for a minimally important difference were developed for benefit outcomes of interest to determine the magnitude of effect and certainty of the evidence. These thresholds were created by task force clinicians and topic experts, taking into account Canadian epidemiologic and natural history data. ${ }^{13,61}$ We did not seek patient input on these thresholds, which for some preventive interventions with substantial harms would be useful to identify patient perspectives of the threshold of benefit.

We did not assess the impact of gonorrhea treatment on antimicrobial resistance, as we focused on patient-important outcomes of screening. It is not necessarily a limitation, but the task force has made a priori choices to pool study data in a way that may differ from other groups. We did not determine the average effect of screening across all included trials because of our predetermined interest in the effects of an offer to screen, regardless of uptake, and the large variability between the trial designs in this respect. Decision-makers less concerned about this variability may have analyzed the data and judged the magnitude of effects differently, although the direction of this recommendation would not likely change.

\section{Conclusion}

Opportunistic screening for chlamydia and gonorrhea among sexually active individuals younger than 30 years confers uncertain but potentially important benefits, particularly for prevention of pelvic inflammatory disease in females. Psychosocial harms of screening are anticipated to be relatively mild, and patients likely prioritize potential screening benefits over harms. The task force conditionally recommends in favour of screening, at primary care visits, sexually active individuals younger than 30 years who are not known to belong to a highrisk group for chlamydia and gonorrhea. Informed consent is required for screening.

\section{References}

1. Choudhri Y, Miller J, Sandhu J, et al. Gonorrhea in Canada, 2010-2015. Can Commun Dis Rep 2018;44:37-42.

2. Choudhri Y, Miller J, Sandhu J, et al. Chlamydia in Canada, 2010-2015. Can Commun Dis Rep 2018;44:49-54.

3. Report on sexually transmitted infections in Canada: 2013-2014. Ottawa: Centre for Communicable Diseases and Infection Control, Infectious Disease Prevention and Control Branch, Public Health Agency of Canada; 2017. Available: www.canada.ca/en/public-health/services/publications/diseases-conditions/ report-sexually-transmitted-infections-canada-2013-14.html (accessed 2020 July 7).

4. Reported cases by age group in Canada - notifiable diseases online. Ottawa: Public Health Agency of Canada; 2019. Available: https://diseases.canada.ca/ notifiable/charts (accessed 2020 July 7).

5. Hocking JS, Temple-Smith M, Guy R, et al. Population effectiveness of opportunistic chlamydia testing in primary care in Australia: a cluster-randomised controlled trial. Lancet 2018;392:1413-22. 
6. Andersen B, van Valkengoed I, Sokolowski I, et al. Impact of intensified testing for urogenital Chlamydia trachomatis infections: a randomised study with 9-year follow-up. Sex Transm Infect 2011;87:156-61.

7. Marrazzo JM. Mucopurulent cervicitis: no longer ignored, but still misunderstood. Infect Dis Clin North Am 2005;19:333-49.

8. Oakeshott P, Kerry S, Aghaizu A, et al. Randomised controlled trial of screening for Chlamydia trachomatis to prevent pelvic inflammatory disease: the POPI (prevention of pelvic infection) trial. BMJ 2010;340:c1642.

9. Price MJ, Ades AE, Welton NJ, et al. Proportion of pelvic inflammatory disease cases caused by Chlamydia trachomatis: consistent picture from different methods. J Infect Dis 2016;214:617-24.

10. Chlamydia control in Europe: literature review. Stockholm: European Centre for Disease Prevention and Control; 2014. Available: https://ecdc.europa.eu/ sites/portal/files/media/en/.../chlamydia-control-europe.pdf (accessed 2019 Nov. 21)

11. Trent M, Bass D, Ness RB, et al. Recurrent PID, subsequent STI, and reproductive health outcomes: findings from the PID evaluation and clinical health (PEACH) study. Sex Transm Dis 2011;38:879-81.

12. Brunham RC, Gottlieb SL, Paavonen J. Pelvic inflammatory disease. N Engl J Med 2015;372:2039-48.

13. Pillay J, Moore A, Rahman P, et al. Screening for chlamydia and/or gonorrhea in primary health care: protocol for systematic review. Syst Rev 2018;7:248. doi: 10.1186/s13643-018-0904-5

14. Fode M, Fusco F, Lipshultz L, et al. Sexually transmitted disease and male infertility: a systematic review. Eur Urol Focus 2016;2:383-93.

15. Miller WC, Ford CA, Morris M, et al. Prevalence of chlamydial and gonococcal infections among young adults in the United States. JAMA 2004;291:2229-36.

16. Denison HJ, Curtis EM, Clynes MA, et al. The incidence of sexually acquired reactive arthritis: a systematic literature review. Clin Rheumatol 2016;35:2639-48.

17. Hannu T. Reactive arthritis. Best Pract Res Clin Rheumatol 2011;25:347-57.

18. O'Connell CM, Ferone ME. Chlamydia trachomatis genital infections. Microb Cell 2016;3:390-403.

19. Götz HM, Veldhuijzen IK, van Bergen JEAM, et al. Acceptability and consequences of screening for Chlamydia trachomatis by home-based urine testing. Sex Transm Dis 2005;32:557-62.

20. Kangas I, Andersen B, Olesen F, et al. Psychosocial impact of Chlamydia trachomatis testing in general practice. Br J Gen Pract 2006;56:587-93.

21. Section 2: Canadian guidelines on sexually transmitted infections - primary care and sexually transmitted infections. Ottawa: Public Health Agency of Canada; 2013. Available: www.canada.ca/en/public-health/services/infectious-diseases/ sexual-health-sexually-transmitted-infections/canadian-guidelines/sexually -transmitted-infections/canadian-guidelines-sexually-transmitted-infections- 17. html (accessed 2020 July 7 )

22. Chlamydia and LGV: screening and diagnostic testing. Ottawa: Public Health Agency of Canada; 2020. Available: www.canada.ca/en/public-health/services/ infectious-diseases/sexual-health-sexually-transmitted-infections/canadian -guidelines/chlamydia-lgv/screening-diagnostic-testing.html (accessed 2020 July 7$)$.

23. Section 5-6: Canadian guidelines on sexually transmitted infections - management and treatment of specific infections - gonococcal infections. Ottawa: Public Health Agency of Canada; 2013. Available: www.canada.ca/en/public -health/services/infectious-diseases/sexual-health-sexually-transmitted-infections/ canadian-guidelines/sexually-transmitted-infections/canadian-guidelines -sexually-transmitted-infections-34.html\#toc361210466 (accessed 2020 July 7).

24. Davies HD, Wang EE. Periodic health examination, 1996 update: 2. Screening for chlamydial infections. Canadian Task Force on the Periodic Health Examination. CMAJ 1996;154:1631-44.

25. Ontario gonorrhea testing and treatment guide. 2nd ed. Toronto: Ontario Agency for Health Protection and Promotion (Public Health Ontario); 2018.

26. Quebec guide to screening for sexually transmitted and blood-borne infections. Québec: Santé et des Services sociaux Québec; 2019. Available: https:// publications.msss.gouv.qc.ca/msss/document-000090/ (accessed 2020 July 7).
27. van den Broek IV, van Bergen JEAM, Brouwers EEHG, et al. Effectiveness of yearly, register based screening for chlamydia in the Netherlands: controlled trial with randomised stepped wedge implementation. BMJ 2012;345: e4316.

28. Ostergaard L, Andersen B, Moller JK, et al. Home sampling versus conventional swab sampling for screening of Chlamydia trachomatis in women: a clusterrandomized 1-year follow-up study. Clin Infect Dis 2000;31:951-7.

29. Hodgins S, Peeling RW, Dery S, et al. The value of mass screening for chlamydia control in high prevalence communities. Sex Transm Infect 2002;78(Suppl 1): i64-8.

30. Klovstad H, Natas O, Tverdal A, et al. Systematic screening with information and home sampling for genital Chlamydia trachomatis infections in young men and women in Norway: a randomized controlled trial. BMC Infect Dis 2013;13:30.

31. Scholes D, Stergachis A, Heidrich FE, et al. Prevention of pelvic inflammatory disease by screening for cervical chlamydial infection. N Engl J Med 1996;334: 1362-6.

32. Senok A, Wilson P, Reid M, et al. Can we evaluate population screening strategies in UK general practice? A pilot randomised controlled trial comparing postal and opportunistic screening for genital chlamydial infection. J Epidemiol Community Health 2005;59:198-204.

33. Clark KL, Howell MR, Li Y, et al. Hospitalization rates in female US Army recruits associated with a screening program for Chlamydia trachomatis. Sex Transm Dis 2002;29:1-5

34. Low N, Egger M, Sterne JAC, et al. Incidence of severe reproductive tract complications associated with diagnosed genital chlamydial infection: the Uppsala Women's Cohort Study. Sex Transm Infect 2006;82:212-8.

35. Sufrin CB, Postlethwaite D, Armstrong MA, et al. Neisseria gonorrhea and Chlamydia trachomatis screening at intrauterine device insertion and pelvic inflammatory disease. Obstet Gynecol 2012;120:1314-21.

36. Andersson N, Carre H, Janlert U, et al. Gender differences in the well-being of patients diagnosed with Chlamydia trachomatis: a cross-sectional study. Sex Transm Infect 2018;94:401-5.

37. Campbell R, Mills N, Sanford E, et al. Does population screening for Chlamydia trachomatis raise anxiety among those tested? Findings from a populationbased chlamydia screening study. BMC Public Health 2006;6:106. doi: 10.1186 /1471-2458-6-106.

38. Fielder RL, Carey KB, Carey MP. Acceptability of sexually transmitted infection testing using self-collected vaginal swabs among college women. J Am Coll Health 2013;61:46-53.

39. France $\mathrm{C}$, Thomas $\mathrm{K}$, Slack R, et al. Psychosocial impacts of chlamydia testing are important. BMJ 2001;322:1245.

40. Gottlieb SL, Stoner BP, Zaidi AA, et al. A prospective study of the psychosocial impact of a positive Chlamydia trachomatis laboratory test. Sex Transm Dis 2011;38:1004-11.

41. Gotz HM, Veldhuijzen IK, van Bergen JEAM, et al.; PILOT CT Study Group. Acceptability and consequences of screening for Chlamydia trachomatis by home-based urine testing. Sex Transm Dis 2005;32:557-62.

42. Low N, Connell P, McKevitt C, et al. 'You can't tell by looking': pilot study of a community-based intervention to detect asymptomatic sexually transmitted infections. Int J STD AIDS 2003;14:830-4.

43. O'Farrell N, Weiss HA. Effect of chlamydia diagnosis on heterosexual relationships. Int J STD AIDS 2013;24:722-6.

44. Walker J, Walker S, Fairley CK, et al. What do young women think about having a chlamydia test? Views of women who tested positive compared with women who tested negative. Sex Health 2013;10:39-42.

45. Torrance GW. Measurement of health state utilities for economic appraisal. $J$ Health Econ 1986;5:1-30.

46. Kuppermann M, Learman LA, Schembri M, et al. Effect of noncancerous pelvic problems on health-related quality of life and sexual functioning. Obstet Gynecol 2007;110:633-42

47. Smith KJ, Tsevat J, Ness RB, et al. Quality of life utilities for pelvic inflammatory disease health states. Sex Transm Dis 2008;35:307-11. 
48. Stratton KR, Durch JS, Lawrence RS. Vaccines for the 21st century: a tool for decisionmaking. Washington (D.C.): National Academies Press; 2000. Available: http:// nationalacademies.org/hmd/Reports/1999/Vaccines-for-the-21st-Century-A-Tool -for-Decisionmaking.aspx (accessed 2019 Nov. 21).

49. Balfe M, Brugha R, O'Donovan D, et al. Young women's decisions to accept chlamydia screening: influences of stigma and doctor-patient interactions. BMC Public Health 2010;10:425.

50. Barth KR, Cook RL, Downs JS, et al. Social stigma and negative consequences: factors that influence college students' decisions to seek testing for sexually transmitted infections. J Am Coll Health 2002;50:153-9.

51. Booth AR, Harris PR, Goyder E, et al. Beliefs about chlamydia testing amongst young people living in relatively deprived areas. J Public Health (Oxf) 2013;35:213-22.

52. Booth AR, Norman P, Harris PR, et al. Using the theory of planned behaviour and self-identity to explain chlamydia testing intentions in young people living in deprived areas. J Health Psychol 2015;20:1229-39.

53. Chacko MR, von Sternberg K, Velasquez MM, et al. Young women's perspective of the pros and cons to seeking screening for chlamydia and gonorrhea: an exploratory study. J Pediatr Adolesc Gynecol 2008;21:187-93.

54. Reed JL, Punches BE, Taylor RG, et al. A qualitative analysis of adolescent and caregiver acceptability of universally offered gonorrhea and chlamydia screening in the pediatric emergency department. Ann Emerg Med 2017;70:787-96.e2.

55. Theunissen KA, Bos AE, Hoebe CJ, et al. Chlamydia trachomatis testing among young people: what is the role of stigma? BMC Public Health 2015;15:651. doi: 10.1186/s12889-015-2020-y.

56. Duncan B, Hart G, Scoular A, et al. Qualitative analysis of psychosocial impact of diagnosis of Chlamydia trachomatis: implications for screening. BMJ 2001;322:195-9.

57. Mills N, Daker-White G, Graham A, et al. Population screening for Chlamydia trachomatis infection in the UK: a qualitative study of the experiences of those screened. Fam Pract 2006;23:550-7.

58. Nielsen A, De Costa A, Danielsson KG, et al. Repeat testing for Chlamydia trachomatis, a "safe approach" to unsafe sex? a qualitative exploration among youth in Stockholm. BMC Health Serv Res 2017;17:730.

59. Einarson K, Buckland D, Scoleri R, et al. Patient preferences for chlamydia and gonorrhea screening and treatment. Toronto; Knowledge Translation Program Li Ka Shing Knowledge Institute St. Michael's Hospital; 2018.

60. Burnett L, Chandraraj A, Stein S, et al. Patient preferences for chlamydia and gonorrhea screening. Toronto; Knowledge Translation Program Li Ka Shing Knowledge Institute St. Michael's Hospital; 2019.

61. Pillay J, Wingert A, MacGregor T, et al. Screening for chlamydia and/or gonorrhea in primary health care: systematic reviews on effectiveness and patient preferences. Syst Rev. In press.

62. Adams EJ, Turner KM, Edmunds WJ. The cost effectiveness of opportunistic chlamydia screening in England. Sex Transm Infect 2007;83:267-74, discussion 274-5.

63. Tuite AR, Jayaraman GC, Allen VG, et al. Estimation of the burden of disease and costs of genital Chlamydia trachomatis infection in Canada. Sex Transm Dis 2012;39:260-7.

64. Lau A, Spark S, Tomnay J, et al. Socio-demographic and structural barriers to being tested for chlamydia in general practice. Med J Aust 2016;204:112.e1-5.

65. Unemo M, Seifert HS, Hook EW, et al. Gonorrhoea. Nat Rev Dis Primers 2019;5:79.

66. Detels R, Green AM, Klausner JD, et al. The incidence and correlates of symptomatic and asymptomatic Chlamydia trachomatis and Neisseria gonorrhoeae infections in selected populations in five countries. Sex Transm Dis 2011;38:503-9.

67. Creighton S, Tenant-Flowers M, Taylor CB, et al. Co-infection with gonorrhoea and chlamydia: How much is there and what does it mean? Int J STD AIDS 2003;14: 109-13.

68. Lyss SB, Kamb ML, Peterman TA, et al. Chlamydia trachomatis among patients infected with and treated for Neisseria gonorrhoeae in sexually transmitted disease clinics in the United States. Ann Intern Med 2003;139:178-85.

69. Forward KR. Risk of coinfection with Chlamydia trachomatis and Neisseria gonorrhoeae in Nova Scotia. Can J Infect Dis Med Microbiol 2010;21:e84-6.
70. Schedule of fees for the laboratory services outpatient payment schedule. Vancouver: British Columbia Ministry of Health; 2020. Available: www.bccss. org/bcaplm-site/Documents/Programs/laboratory_services_schedule_of_fees .pdf (accessed 2020 July 7).

71. Jackson LJ, Auguste P, Low N, et al. Valuing the health states associated with Chlamydia trachomatis infections and their sequelae: a systematic review of economic evaluations and primary studies. Value Health 2014;17:116-30.

72. Schünemann H, Brozek J, Guyatt G, et al. GRADE handbook: handbook for grading the quality of evidence and strength of recommendations using the GRADE approach. GRADE Working Group; 2013. Available: http://gdt. guidelinedevelopment.org/app/handbook/handbook.html (accessed 2019 Nov. 21).

73. Andrews JC, Schünemann HJ, Oxman AD, et al. GRADE guidelines: 15. going from evidence to recommendation - determinants of a recommendation's direction and strength. J Clin Epidemiol 2013;66:726-35.

74. Thombs BD, Straus SE, Moore AE; Canadian Task Force on Preventive Health Care; Collaborating Members of the Canadian Task Force for Preventive Health Care. Update on task force terminology and outreach activities: advancing guideline usability for the Canadian primary care context. Can Fam Physician 2019;65:12-13; E7.

75. Buckland D, Bashir N, Moore JE, et al. CTFPHC patient engagement protocol. Toronto: Li Ka Shing Institute, St. Michael's Hospital; 2017. Available: http:// canadiantaskforce.ca/methods/patient-engagement-protocol/ (accessed 2020 Nov. 24).

76. Schünemann HJ, Al-Ansary LA, Forland F, et al. Guidelines International Network: Principles for disclosure of interests and management of conflicts in guidelines. Ann Intern Med 2015;163:548-53.

77. Canadian Task Force on Preventive Health Care: Policy on disclosures of interests and management of conflicts of interest. Canadian Task Force on Preventive Health Care; 2020. Available: https://canadiantaskforce.ca/about/conflict -of-interest-policy/ (accessed 2020 Nov. 24).

78. Hood JE, Friedman AL. Unveiling the hidden epidemic: a review of stigma associated with sexually transmissible infections. Sex Health 2011;8:159-70.

79. Heritage J, Jones M. A study of young peoples' attitudes to opportunistic chlamydia testing in UK general practice. Reprod Health 2008;5:11.

80. Paudyal P, Llewellyn C, Lau J, et al. Obtaining self-samples to diagnose curable sexually transmitted infections: a systematic review of patients' experiences. PLoS One 2015;10:e0124310.

81. Pimenta JM, Catchpole M, Rogers PA, et al. Opportunistic screening for genital chlamydial infection. I: acceptability of urine testing in primary and secondary healthcare settings. Sex Transm Infect 2003;79:16-21.

82. Nelson HD, Zakher B, Cantor AG, et al. Screening for gonorrhea and chlamydia: systematic review to update the U.S. Preventive Services Task Force recommendations. Rockville (MD): Agency for Healthcare Research and Quality; 2014. Available: www.ncbi.nlm.nih.gov/books/NBK248303/ (accessed 2019 Nov. 21).

83. Canadian guidelines on sexually transmitted infections: summary of recommendations for Chlamydia trachomatis (CT), Neisseria gonorrhoeae (NG) and syphilis. Ottawa: Public Health Agency of Canada; 2019. Available: www. canada.ca/content/dam/phac-aspc/documents/services/publications/diseases -conditions/sti/64-02-18-2248-STI-Recommendations-Tip-Sheet-EN-Final.pdf (accessed 202 July 7).

84. Draft update summary: chlamydial and gonococcal infections: screening. Rockville (MD): U.S. Preventive Services Task Force; updated 2019 May 2. Available: www. uspreventiveservicestaskforce.org/Page/Document/UpdateSummaryDraft/ chlamydial-and-gonococcal-infections-screening (accessed 2019 Nov. 21).

85. National chlamydia screening programme standards (seventh edition). London (UK): Public Health England; 2018. Available: https://assets.publishing.service. gov.uk/government/uploads/system/uploads/attachment_data/file/759846/ NCSP_Standards_7th_edition_update_November_2018.pdf (accessed 2020 July 7).

86. Australian STI management guidelines for use in primary care: chlamydia. Sydney (AU): Australasian Sexual Health Alliance; 2018; Available: www.sti.guidelines.org. au/sexually-transmissible-infections/chlamydia (accessed 2020 July 7). 
Authors: Ainsley Moore MD MSc, Gregory Traversy MSc, Donna L. Reynolds MD MSc, John J. Riva DC PhD, Guylène Thériault MD, Brenda J. Wilson MB ChB MSc MRCP (UK), Melissa Subnath MSc, Brett D. Thombs PhD

Competing interests: None declared.

This article has been peer reviewed.

Affiliations: Department of Family Medicine (Moore), McMaster University, Hamilton, Ont.; Public Health Agency of Canada (Subnath, Traversy), Ottawa, Ont.; Department of Family and Community Medicine (Reynolds), University of Toronto, Toronto, Ont.; Department of Family Medicine (Riva), McMaster University, Hamilton, Ont.; Faculty of Medicine (Thériault) McGill University, Montréal, Que.; Division of Community Health and Humanities (Wilson), Memorial University, NFLD; Lady Davis Institute and Department of Psychiatry (Thombs), Jewish General Hospital and McGill University, Montréal, Que.

Guideline Writing Group: Ainsley Moore (voting task force member), Gregory Traversy (nonvoting science team member), Donna L. Reynolds (voting task force member), John J. Riva (voting task force member), Guylène Thériault (voting task force member), Brenda J. Wilson (voting task force member), Melissa Subnath (nonvoting science team member), Brett $D$. Thombs (voting task force member).

Collaborating Members of the Canadian Task Force on Preventive Health Care: Ahmed M. Abou-Setta, Heather Colquhoun, Roland Grad, Scott Klarenbach, Christina Korownyk, Eddy Lang, John C. LeBlanc, Navindra Persaud.

Contributors: Ainsley Moore, Gregory Traversy, Donna Reynolds, John Riva, Guylène Thériault, Brenda Wilson, Melissa Subnath, and Brett Thombs contributed substantially to the study concept and design, interpretation of the evidence, and critical revision of the guideline draft. Gregory Traversy and Melissa Subnath provided science and logistical support to the writing group. Ainsley Moore, Donna Reynolds, John Riva, Guylène Thériault, Brenda Wilson, and Brett Thombs drafted the recommendations. Ainsley Moore and Gregory Traversy drafted the guideline statement. All of the named authors gave final approval of the version of the guideline to be published and agreed to be accountable for all aspects of the work. All collaborating members of the Canadian Task Force on Preventive Health Care (Ahmed M. Abou-Setta, Heather Colquhoun, Roland Grad, Scott Klarenbach, Christina Korownyk, Eddy Lang, John C. LeBlanc, Navindra Persaud) also made contributions to the development of the guideline and all gave final approval of the version of the guideline to be published.

Funding: Funding for the Canadian Task Force on Preventive Health Care is provided by the Public Health Agency of Canada. The views of the funding body are not considered by the task force in developing its recommendations. The views expressed in this article are those of the task force and do not necessarily represent those of the Public Health Agency of Canada.
Content licence: This is an Open Access article distributed in accordance with the terms of the Creative Commons Attribution (CC BY 4.0) licence, which permits others to distribute, remix, adapt and build upon this work, for commercial use, provided the original work is properly cited. See: http://creativecommons.org/licenses/by/4.0/

Acknowledgements: The authors thank the Alberta Evidence Review and Synthesis Centre team (Jennifer Pillay, Aireen Wingert, Tara MacGregor, Michelle Gates, Ben Vandermeer, Lisa Hartling) for its evidence review, which supported this guideline; Susan Courage, Prinon Rahman, Rachel Rodin, and Elizabeth Rolland-Harris of the Global Health and Guidelines Division at the Public Health Agency of Canada, who supported the development of the guideline; and the Knowledge Translation Program, Li Ka Shing Knowledge Institute, St. Michael's Hospital, for their contributions to patient engagement and knowledge translation work related to this guideline; and task force interns Geneviève Cadieux (Ottawa Public Health, Ottawa, Ont.) and Amanda Ramdyal (Department of Family Medicine, McMaster University, Hamilton, Ont.) for their support of the working group. The authors thank Dr. Ann Burchell (University of Toronto, Toronto, Ont.), Dr. Jo-Anne Dillon (University of Saskatchewan, Saskatoon, Sask.), Dr. Ameeta Singh (University of Alberta, Edmonton, Alta.) and Dr. Tom Wong (Indigenous Services Canada, Ottawa, Ont.) for assisting as clinical or content experts during the development of this guideline. Clinical and content experts who have assisted the task force in the guideline process may or may not agree with the task force recommendations. Additionally, the authors thank the peer reviewers and organizational stakeholders who reviewed provided feedback on the draft guideline, including Lana Beth Barkhouse, College of Family Physicians of Canada, Mississauga, Ont.; Marilyn Barrett, Department of Health and Wellness, Charlottetown, PEl; Katherine Bell, College of Family Physicians of Canada, Mississauga, Ont.; Anne Bruneau, Institut national de santé publique du Québec, Québec City, Que.; Monica Durigon, Community Health Nurses of Canada, Toronto, Ont.; Natalie Fawcett, Community Health Nurses of Canada and Toronto Public Health, Toronto, Ont.; Claude Laberge, Ministère de la Santé et des services sociaux, Québec City, Que.; Unjali Malhotra, Indigenous Physicians Association of Canada, West Vancouver, BC; Christelle Kom Mogto, Centre intégré de santé et de services sociaux de l'Outaouais, Gatineau, Que.; Joan Robinson, Canadian Paediatric Society, Ottawa, Ont.; Barbara Romanowski, University of Alberta, Edmonton, Alta.; Paula Schwann, College of Family Physicians of Canada, Mississauga, Ont.; Marc Steben, Université de Montréal, Montréal, Que.; Sharon Vipler, College of Family Physicians of Canada, Mississauga, Ont.; Dennis Williams, Planned Parenthood Toronto, Toronto, Ont.; and Mark Yudin, University of Toronto, Toronto, Ont.

Disclaimer: Navindra Persaud is an associate editor for CMAJ and was not involved in the editorial decision-making process for this article.

Correspondence to: Task Force on Preventive Health Care, info@canadiantaskforce.ca 